bility, as noticeable deviation in progesterone levels was shown in one control cycle (Fig. 6), although in another case studied little change was noted.

The fall in levels during the infusion was more precipitous than that observed during untreated menstrual cycles. After the infusion in the late luteal phase levels continued to fall in three of the four volunteers, whereas in the subjects in the early luteal phase progesterone levels rose subsequent to the infusion. LeMaire and Shapiro (1972) found little cyclic variation in progesterone levels in patients infused with saline in the luteal phase, whereas Henzl et al. (1972) showed pronounced spontaneous fluctuation.

In the present study, despite the decrease in progesterone levels, the luteal phase of the menstrual cycle was not reduced. While the work reported in this paper was in progress, LeMaire and Shapiro (1972) published a similar study of five volunteers using low doses of $\mathrm{PGF}_{2} \alpha(25-46 \mu \mathrm{g} / \mathrm{min})$ infused in the early luteal phase and one infused in the late luteal phase; prostaglandins had no effect. In the fifth subject, also in the late luteal phase, infused when progesterone levels were already declining, a drop in progesterone was noted; the luteal phase length was not reduced.

Prostaglandin $F_{2} \alpha$ was infused intravenously during the early luteal phase in six non-pregnant women (Wiqvist et al., 1970). Four subjects were infused with 9-12 $\mu \mathrm{g} / \mathrm{min}$ and two with 50-100 $\mu \mathrm{g} / \mathrm{min}$ for a period of eight hours a day on two successive days. A slight transient decrease in plasma progesterone occurred. The luteal phase length was not reduced.

Henzl et al. (1972) noted no shortening of the luteal phase or fall in plasma progesterone beyond normal variability in seven volunteers infused with $\mathrm{PGE}_{2}$. They did not find intermenstrual bleeding in any volunteer infused with $\mathrm{PGE}_{\text {, }}$ unlike the present series where four subjects experienced premenstrual loss. The disparity could be due to differences in prostaglandins used and the severity of uterine contractions.

This study indicates that systemically-administered prostaglandin $F_{2} \alpha$ is unsuitable for depressing the progesterone synthesizing capability of the human corpus luteum. High doses are required before progesterone levels are affected; and this is associated with side effects similar to those seen during $\mathrm{PGF}_{2} \alpha$ infusion in early pregnancy (Hillier and Embrey, 1972).

The naturally occurring prostaglandins are local hormones, and it is possible that the tissue level achieved at the site of action-for example, in the corpus luteum or pituitary-may be critical. However, if high systemic levels are required to produce such tissue concentrations then concomitant adverse side effects will occur. It is possible that more prolonged application of a low dosage of $\mathrm{PGF}_{2} \alpha$-for example, via a vaginal pessary-may be more acceptable, but this is unlikely to be adequately effective considering the rapid inactivation of it in the lungs and liver.

There are pronounced species differences in the luteolytic capacity of systemically-applied $\mathrm{PGF}_{2} \alpha$. It seems likely that it is potently luteolytic only where a uterine component for regression exists.

It is likely that an effect will be seen only over a limited period of time in the luteal phase, possibly where relative levels of other factors allow an optimum response.

A long-acting prostaglandin analogue with high luteolytic activity but low smooth muscle stimulating activity in the primate will be of interest to investigators in this field.

We are extremely grateful to the volunteers without whom this study would not have been possible. We thank Mr. John Bonnar, consultant gynaecologist, for useful comments on the manuscript, and Dr. Rex Jacomb, of the Upjohn Company Ltd., for supplies of prostaglandins.

This work has been supported by the Agency for International Development Contract No. AID/csd 2837 (granted to K.H. and M.P.E.).

\section{References}

Abraham, G. E., Odell, W. D., Edwards, R., and Purdy, J. M. (1970). Acta Endocrinologica (Kobenhavn), Suppl. No. 147, p. 332.

Blatchley, F. R., and Donovan, B. T. (1969). Nature, 221, 1065.

Corker, C. S., Exley, D., and Naftolin, F. (1970). In Karolinska Symposium on Research Methods in Reproductive Endocrinology, ed. E. Diczfalusy. p. 305. Copenhagen, Bogtrykkeriet Forum.

Henzl, M. R., Ortega, E., Cortes-Gallegos, V., Tomlinson, R. V., and Segre, E. J. (1972). In press.

Hillier, K., and Embrey, M. P. (1972). Fournal of Obstetrics and Gynaecology of the British Commonwealth, 79, 14.

Johansson, E. D. B. (1969). Acta Endocrinologica (Kobenhavn), 61, 592.

Karim, S. M. M. (1971). Contraception, 3, 173.

Kirton, K. T. (1972). In Prostaglandins in Fertility Control, vol. 2. Stockholm, W.H.O. Research and Training Centre on Human Reproduction.

Kirton, K. T., Pharriss, B. B., and Forbes, A. D. (1970). Proceedings of the Society for Experimental Biology and Medicine, 133, 314.

Lehmann, F., Peters, F., Breckwoldt, M., and Bettendorf, G. (1972). Prostaglandins, 1,269.

LeMaire, W. J., and Shapiro, A. G. (1972). Prostaglandins, 1, 259.

McCracken, J. A., Glew, M. E., and Scaramuzzi, R. J. (1970). Fournal of Clinical Endocrinology and Metabolism, 30, 544.

Midgley, A. R. (1966). Endocrinology, 79, 10.

Pharriss, B. B., and Wyngarden, L. J. (1969). Proceedings of the Society for Experimental Biology and Medicine, 130, 92.

Wiqvist, N., Bygdeman, M., and Kirton, K. T. (1970). In Nobel Symposium, ed. E. Diczfalusy and V. Borell, vol. 15, p. 137. New York, John Wiley.

\title{
Comparison between Urinary Oestrogen Assay and Serial Ultrasonic Cephalometry in Assessment of Fetal Growth Retardation
}

\author{
STUART CAMPBELL, ASIM KURJAK
}

British Medical fournal, 1972, 4, 336-340

\section{Summary}

Urinary oestrogen assay and serial ultrasonic cephalometry were performed on 284 patients who were considered on clinical grounds to be at risk of having a

Institute of Obstetrics and Gynaecology, Queen Charlotte's Maternity Hospital, London W.6

STUART CAMPBELL, M.B., M.R.C.O.G., Senior Lecturer ASIM KURJAK, M.D., British Council Scholar growth-retarded fetus. It was found that ultrasonic cephalometry was significantly better than oestrogens in diagnosing the small-for-dates baby, but that there was no significant difierence between the two methods in predicting perinatal asphyxia. Of the 14 stillbirths, three were in the normal ultrasonic growth rate group and five had normal oestrogen excretion. Both methods were found to be of value in the diagnosis of fetal growthretardation, although cephalometry would seem to have some advantages, especially in distinguishing between fetal growth-retardation and mistaken maturity. 


\section{Introduction}

Fetal growth-retardation is usually caused by uteroplacental insufficiency and results in the birth of a baby that is small for its gestational age (small for dates). These babies have a high incidence of perinatal death (Gruenwald, 1969), intrapartum asphyxia (Low et al., 1972), and are at increased risk in the neonatal period from pulmonary haemorrhage, hypoglycaemia, hypocalcaemia, and fetal abnormality (Bard, 1970). In the long term there is evidence that severely growth-retarded babies suffer from intellectual impairment (Weiner, 1970), especially if management is less than adequate. Early and accurate recognition of fetal growth-retardation will therefore reduce perinatal mortality and morbidity by permitting delivery of the fetus at the optimal time to give the highest chance of survival and the lowest risk of sequelae.

Unfortunately, diagnosis of fetal growth-retardation by palpation of the uterus is unreliable (Campbell, 1971), and various biochemical and biophysical investigations are now used to help in the diagnosis of this condition. Of the many biochemical placental function tests now available, urinary oestrogen assay is the most commonly used, and was regarded by Turnbull (1971) as the most reliable. This is almost certainly due to the fact that the fetus plays an active part in the synthesis of oestrogens (Diczfalusy, 1969), and so the measurement of oestrogens is a reflection of the integrity of the fetoplacental unit. Serial ultrasonic cephalometry is at present only practised in a few centres, but published work (Willocks et al., 1967; Campbell and Dewhurst, 1971) indicates that this is the most accurate method of physically measuring fetal growth.

In view of the importance of these two diagnostic techniques we decided to compare the value of urinary oestrogen assay and serial ultrasonic cephalometry in the diagnosis of fetal growth-retardation.

\section{Patients and Methods}

A total of 284 patients were assessed by urinary oestrogen assay and serial ultrasonic cephalometry because it was believed that the fetus was at risk from fetal growth-retardation. Of these, 268 were regarded by experienced obstetricians as having a uterus that was persistently smaller than normal for the gestational age. The remaining 16 patients with clinically normal sized babies were referred because they had diabetes mellitus or had a bad obstetric history. A list of the obstetric complications is given in Table I. Patients with twin pregnancy or Rhesus isoimmunization were not included. Most of the patients studied were attending Queen Charlotte's Maternity Hospital but 51 were referred from other hospitals.

TABLE I-Complications of Pregnancy and Management

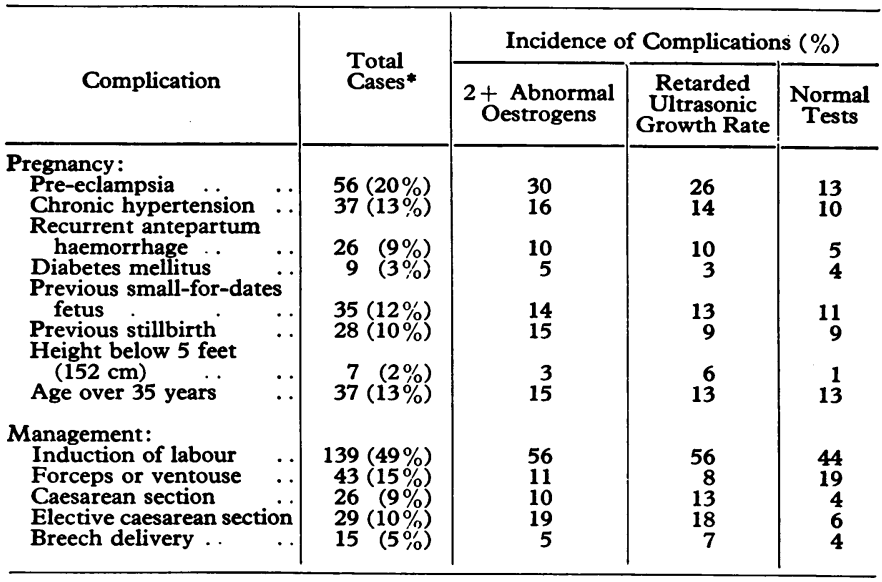

- Some patients had more than one complication.
Urinary Oestrogen Assay.-All patients had at least three urinary oestrogen estimations performed as an inpatient, urine collections being made two or three times each week. In each case estimations were continued to within one week of delivery. The average number of estimations per patient was seven. In 249 cases total urinary oestrogens were estimated by the method of Brown et al. (1968) and in nine cases by the method of Oakey et al. (1967). In 26 cases, oestrogens were measured as oestriol by the method of Brown and Coyle (1963). In each case the results were compared with the normal range of values for each laboratory according to the technique used. Initially, patients were grouped as to whether they had none, one, two, three, or more oestrogens below the lower limit of normal with the stipulation that for a case to be recorded as having two or more oestrogen levels below normal successive low oestrogens had to be within two weeks of each other. It was found that when patients who had no abnormal oestrogen levels were compared with patients who had one oestrogen below the normal range there was no significant difference in the incidence of small-for-dates babies $\left(\chi^{2}=1.46 \mathrm{P}>0.2\right)$ or low Apgar scores $\left(\chi^{2}=0.07 \mathrm{P}>0.7\right)$. Consequently, for the predictive assessment of oestrogens they were classified as normal (none or one below the normal range), $2+$ abnormal (two or more below the normal range), and $3+$ abnormal (three or more below the normal range).

Serial Ultrasonic Cephalometry.-Measurement of the fetal biparietal diameter was made by the combined A and B scan method (Campbell, 1968), and all measurements were taken by one of us (S.C.). The ultrasonic apparatus used was the Diasonograph 4101 (Nuclear Enterprises Limited). The method of classifying each patient into a percentile ultrasonic growth rate category is described by Campbell and Dewhurst (1971). In this previous study three ultrasonic growth rate groups were described; normal (above the 10th percentile), borderline (between the 5th and 10th percentile), and retarded (below the 5th percentile). It was found that the borderline growth rate group was usually associated with the delivery of a normal sized baby, and in the present study it was decided to regard these cases as normal. Ultrasonic growth rates were therefore classified as normal (above the 5th percentile) and retarded (5th percentile or less).

Fetal Criteria.-The predictive value of the two techniques was assessed against the following criteria of fetal wellbeing. (1) The birth weight for gestation. This was classified according to the tables of Thomson et al. (1968), corrections being made for maternal parity and fetal sex. The few cases that delivered before 32 weeks' gestation were grouped according to the tables of Gruenwald (1966). In 31 cases, the pregnancy was allowed to proceed to 43 weeks or more (see below). In order to eliminate bias these cases were regarded as being 42 weeks' mature when assessed against the weight for gestation tables. Birth weights above the 5th percentile were classified as normal and those on or below the 5 th percentile as small for dates. (2) The one-two minute Apgar score. Cases of gross fetal abnormality were excluded. Apgar scores of six or more were regarded as normal while those below six were classified as abnormal. (3) The number of perinatal deaths. Cases of gross fetal abnormality were excluded. (4) The number of gross fetal abnormalities. These criteria were chosen because they can be assessed objectively, and were applied to all babies in the study.

\section{Results}

Of the 284 cases studied, 87 ( $31 \%$ ) were small for dates and $46(17 \%)$ had a low Apgar score. There were 14 perinatal deaths $(5 \cdot 1 \%)$ and 8 gross fetal abnormalities $(2 \cdot 8 \%)$.

The overall incidence of pregnancy complications (including surgical intervention) is given in Table I. There was a significant increase in the incidence of pre-eclampsia, induction of labour, caesarean section (both elective and emergency), and a reduction 
in the incidence of instrumental deliveries in patients who had abnormal oestrogens or retarded ultrasonic growth rates when compared with patients classified as normal.

Birth Weight.-Among the 87 babies that were small for dates, $65(75 \%)$ had a retarded ultrasonic growth rate while $46(53 \%)$ had $2+$ abnormal oestrogens and $37(43 \%)$ had 3 + abnormal oestrogens (Table II). Cases classified as abnormal by either method showed a statistically highly significant association with the birth of a small-for-dates fetus $(P<0.001)$. However, when the results are expressed as false-positive and false-negative diagnoses (Fig. 1) it is clear that there is a noticeable increase in the number of false-negative diagnoses in the abnormal oestrogen groups when compared with the retarded

TABLE II-Urinary Oestrogens, Ultrasonic Cephalometry, and Birth Weight in 284 Cases

\begin{tabular}{|c|c|c|c|c|c|c|}
\hline \multirow{2}{*}{$\begin{array}{c}\text { Birth } \\
\text { Weight }\end{array}$} & \multirow{2}{*}{$\begin{array}{l}\text { No. of } \\
\text { Cases }\end{array}$} & \multicolumn{3}{|c|}{ Urinary Oestrogen Excretion } & \multicolumn{2}{|c|}{$\begin{array}{l}\text { Ultrasonic Growth } \\
\text { Rate }\end{array}$} \\
\hline & & Normal & $\stackrel{2+}{2+}$ & $\stackrel{3+}{\text { Abnormal }}$ & Normal & Retarded \\
\hline $\begin{array}{l}\text { Normal } \\
\text { Small for dates }\end{array}$ & $\begin{array}{c}197 \\
(100 \%) \\
87 \\
(100 \%)\end{array}$ & $\begin{array}{c}163 \\
(83 \%) \\
41 \\
(47 \%)\end{array}$ & $\begin{array}{c}34 \\
(17 \%) \\
46 \\
(53 \%)\end{array}$ & $\begin{array}{c}18 \\
(9 \%) \\
37 \\
(43 \%)\end{array}$ & $\begin{array}{c}165 \\
(84 \%) \\
22 \\
(25 \%)\end{array}$ & $\begin{array}{c}32 \\
(16 \%) \\
65 \\
(75 \%)\end{array}$ \\
\hline
\end{tabular}

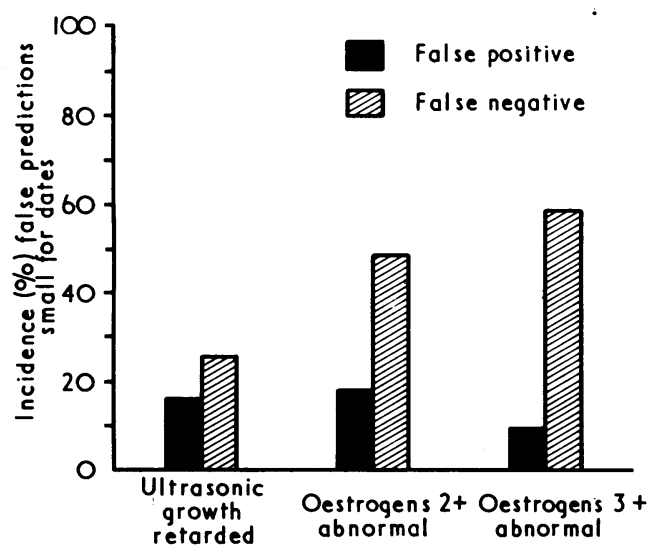

FIG. 1-Incidence of false predictions of small-for-dates baby in retarded ultrasonic growth and abnormal oestrogen groups.

ultrasonic growth group. A statistical comparison between the two methods can be made if we study the 97 cases where the predictions based on the ultrasonic and oestrogen results disagreed. Of the 37 small-for-dates babies in this group, 28 were in the retarded ultrasonic growth group and only nine were in the $2+$ abnormal oestrogen group. A significantly higher number of these babies were correctly categorized by ultrasonic cephalometry $\left(\chi^{2}=8.48 \mathrm{P}<0.005\right)$.

Apgar Score.-Of the 46 cases with abnormal Apgar score, $25(54 \%)$ were in the retarded ultrasonic growth rate category, while $23(50 \%)$ had $2+$ abnormal oestrogens and $16(35 \%)$ had $3+$ abnormal oestrogens (Table III). Cases in the retarded ultrasonic growth rate and $2+$ abnormal oestrogen groups showed a highly significant association with a low Apgar score $(\mathrm{P}<$ 0.001). Further analysis (Fig. 2) shows that a higher percentage of babies with a very low Apgar score (1-4) were in the retarded ultrasonic growth category, when compared with $2+$ abnormal oestrogens, but this advantage is to some extent offset by a higher number of retarded growth babies in the Apgar 8-10 group. A statistical analysis of the results from the 88 babies in which ultrasound and oestrogen predictions disagreed showed that nine of the 16 babies with an abnormal Apgar score were correctly categorized by ultrasonic cephalometry and seven by oestrogen assay. These differences are not statistically significant $\left(\chi^{2}=0.002 ; P>0.9\right)$. Furthermore, when all cases of elective caesarean section and breech delivery (which may lower the Apgar score for reasons other than stress hypoxia) were removed from the analysis, there was still no significant difference in the distribution of normal and low Apgar scores between the two methods ( $P>0.9)$.

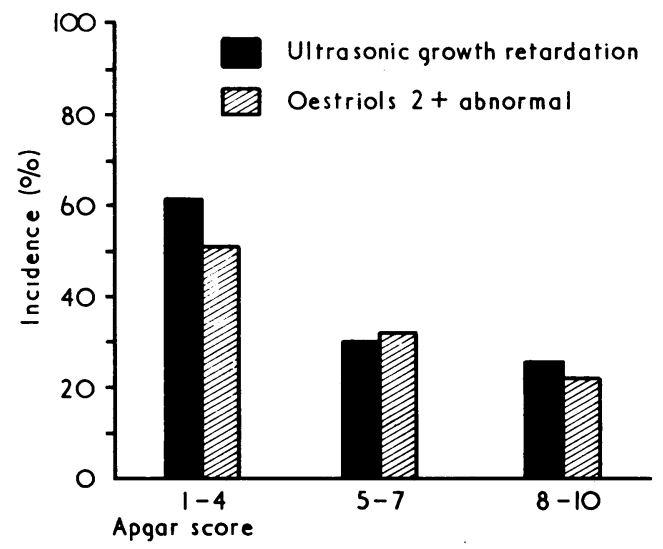

FIG. 2-Incidence of fetuses with retarded ultrasonic growth and $2+$ abnormal oestrogens in low, intermediate, and high Apgar score groups.

TABLE III-Urinary Oestrogens, Ultrasonic Cephalometry, and Apgar Score in 265 Cases

\begin{tabular}{|c|c|c|c|c|c|c|}
\hline \multirow{2}{*}{$\begin{array}{l}\text { Apgar } \\
\text { Score }\end{array}$} & \multirow{2}{*}{$\begin{array}{l}\text { No. of } \\
\text { Cases }\end{array}$} & \multirow{2}{*}{\begin{tabular}{|} 
Urinary \\
Normal
\end{tabular}} & \multicolumn{2}{|c|}{ Ostrogen Excretion } & \multicolumn{2}{|c|}{$\begin{array}{l}\text { Ultrasonic Growth } \\
\text { Rate }\end{array}$} \\
\hline & & & $\stackrel{2+}{2+}$ & $\stackrel{3+}{3+}$ & Normal & Retarded \\
\hline $\begin{array}{l}\text { Normal } \\
\text { Abnormal } \\
(<6)\end{array}$ & $\begin{array}{c}219 \\
(100 \%) \\
46 \\
(100 \%)\end{array}$ & $\begin{array}{c}169 \\
(77 \%) \\
23 \\
(50 \%)\end{array}$ & $\begin{array}{c}50 \\
(23 \%) \\
23 \\
(50 \%)\end{array}$ & $\begin{array}{c}35 \\
(16 \%) \\
16 \\
(35 \%)\end{array}$ & $\begin{array}{c}161 \\
(74 \%) \\
21 \\
(46 \%)\end{array}$ & $\begin{array}{c}58 \\
(26 \%) \\
25 \\
(54 \%)\end{array}$ \\
\hline
\end{tabular}

Perinatal Mortality.-Of the 11 stillbirths, eight were small for dates-seven dying antenatally because of chronic placental failure and the eighth dying in labour from acute on chronic fetal distress. The remaining three stillbirths were of normal weight, death in each case being due to abruptio placentae. All the stillbirths occurred between 31 and 34 weeks' gestation (Table IV). Three of the stillbirths were in the normal ultrasonic growth category; two of these were of normal weight for gestation, death being due to abruptio placentae, while the

TABLE IV-Urinary Oestrogens, Ultrasonic Cephalometry, and Perinatal Mortality in 14 Cases

\begin{tabular}{|c|c|c|c|c|c|c|}
\hline & \multirow{2}{*}{$\begin{array}{l}\text { No. of } \\
\text { Cases }\end{array}$} & \multicolumn{3}{|c|}{ Urinary Oestrogen Excretion } & \multicolumn{2}{|c|}{$\begin{array}{l}\text { Ultrasonic Growth } \\
\text { Rate }\end{array}$} \\
\hline & & Normal & $\stackrel{2+}{2+}$ & $\stackrel{3+}{3+}$ & Normal & Retarded \\
\hline \multirow{2}{*}{$\begin{array}{l}\text { Stillbirth } \\
\text { Neonatal death } \\
\text { (1st week) }\end{array}$} & 11 & 5 & 6 & 5 & 3 & 8 \\
\hline & 3 & $\mathbf{0}$ & 3 & 3 & $\mathbf{0}$ & 3 \\
\hline Total & $14(100 \%)$ & $5(36 \%)$ & $9(64 \%)$ & $8(57 \%)$ & $3(21 \%)$ & $11(79 \%)$ \\
\hline
\end{tabular}

other was small for dates. In this latter case intrauterine death occurred at 34 weeks, and it is likely that the reassuring ultrasonic measurements contributed to the delay in delivery (although only two measurements were taken and these were separated by only one week). Five of the stillbirths were in the normal oestrogen group; three were due to abruptio placentae (birth weight normal) while two were small for dates. In the first of the small for dates stillbirths intrauterine death occurred at 32 weeks, a urinary oestrogen taken 48 hours before delivery being above the mean for 32 weeks. The second case is shown below (Case 2, Fig. 4). The three neonatal deaths occurred in babies that were small for dates and all were in the abnormal ultrasonic and oestrogen groups. In each case death could be 
attributed to the small-for-dates syndrome. The first died from intraventricular haemorrhage at 38 weeks' gestation after severe intrapartum hypoxia, the second died from pulmonary haemorrhage at 36 weeks' gestation, and the third died from a general haemorrhagic diathesis at 33 weeks.

Fetal Abnormality.-There were eight gross fetal abnormalities. Two were autosomal trisomies (D and E), two had renal agenesis, one had microcephaly, while the remainder had multiple skeletal and central nervous system defects. Five of the abnormal babies were in the retarded ultrasonic growth category, while only two had $2+$ abnormal oestrogens and none had $3+$ abnormal oestrogens.

\section{Case Reports}

Case 1. The patient was aged 40 and her only previous pregnancy had resulted in a postmature, small-for-dates stillbirth. Fetal growth was monitored by ultrasound from 19 weeks menstrual age. There was a sharp fall in the growth rate at 32 weeks and total cessation at 35 weeks. The six urinary oestrogens were all within normal limits (Fig. 3). Spontaneous labour occurred at 38 weeks. Fetal distress developed (type II dips on the fetal heart monitor, $\mathrm{pH} 7 \cdot 23$ ), and emergency caesarean section was performed. The baby was asphyxiated at birth (Apgar 2), and despite immediate intubation made slow recovery (Apgar 5 at 5 minutes). Subsequent progress was good. The birth weight was $2.39 \mathrm{~kg}$ - that is, small for dates.

Case 2.-The patient was multiparous, aged 25 . Early pregnancy was complicated with recurrent bleeding. An early ultrasonic measurement at 17 weeks' menstrual age was two weeks smaller than average, but as subsequent growth to 32 weeks was normal it was suspected that she was two weeks less than her menstrual dates. Ultrasonic growth, however, was virtually static over the next three weeks. Urinary oestrogens (apart from a single early low reading) were normal (Fig. 4). The patient went into spontaneous labour at 35 weeks' menstrual age and, although no abnormal fetal heart patterns were noted, the fetal heart suddenly stopped when the cervix was $3 \mathrm{~cm}$
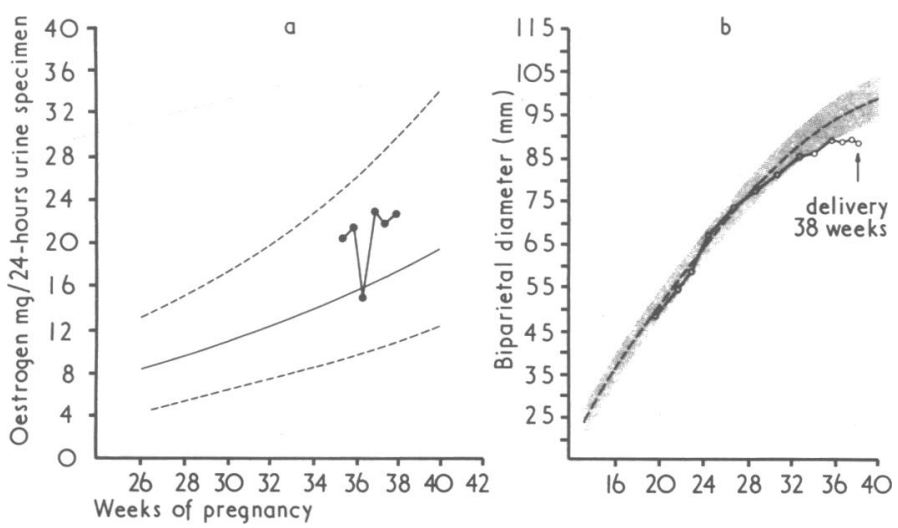

FIG. 3-Case 1. Urinary oestrogen values and serial ultrasound cephalometry values related to normal range for each week of gestation.
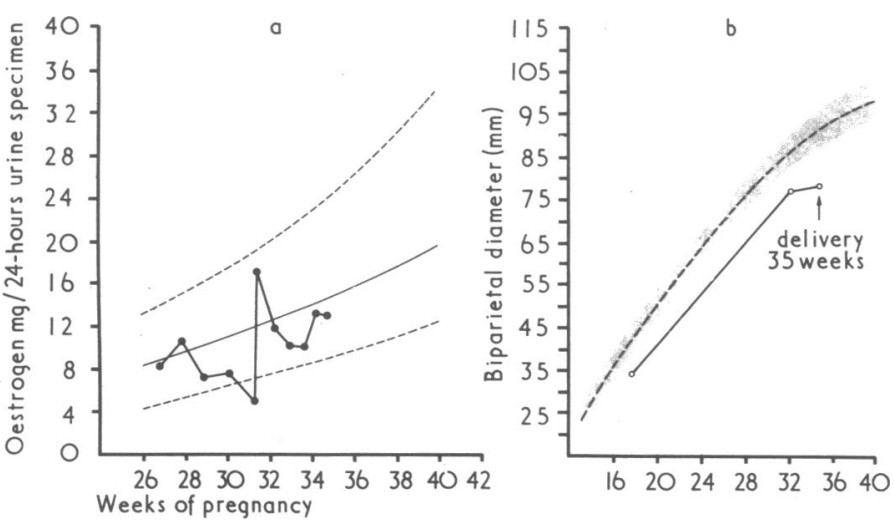

FIG. 4-Case 2. Urinary oestrogen values and serial ultrasound cephalometry values related to normal range for each week of gestation. dilated. The pathologist's estimate of maturity was 32-34 weeks, which agrees with the ultrasonic maturity. The birth weight was $1.42 \mathrm{~kg}$, which is small for dates (even for 33 weeks' maturity).

\section{Discussion}

Comparison between methods of assessing fetal wellbeing is notoriously difficult because obstetricians cannot be denied information which may be instrumental in saving life. Both urinary oestrogens and ultrasonic cephalometry have previously been shown to be reliable methods of assessing fetal growthretardation (Michie, 1967; Klopper, 1965; Willocks et al., 1967; Campbell and Dewhurst, 1971), and so one must assume that the management of these cases was influenced by the results of these tests. From Table I, however, it can be seen that the incidence of surgical intervention was very similar in both the abnormal oestrogen and retarded ultrasonic groups. This suggests that the obstetricians were equally motivated by both methods in their management of the patients, and we therefore feel that this comparative assessment is valid.

Another difficulty lay in the optimal classification of oestrogens for predictive value. Despite the abundance of literature on the subject of oestrogens in pregnancy there is no universally accepted classification. Some authors (Michie, 1967; Elder, 1971) only accept low oestrogens if they are obtained shortly before delivery, but we felt that in a predictive test low values at any stage must be regarded as significant. Similarly, it is often stated that if values are seen to be falling they should be regarded as indicating placental failure, and, conversely, if they are rising that all is well. For objective classification, however, this is vague and unsatisfactory. If a series of oestrogens are below normal but climbing, it is our experience that the situation cannot be regarded with equanimity. Similarly, if all the values are in the normal range but "falling," we have usually found that the outcome was satisfactory. In fact, oestrogen values have a daily coefficient of variation of $30 \%$ (Klopper, 1969) and often fluctuate widely, so that the determination of whether values are rising or falling is frequently difficult. We have found from the present study that two or more abnormal oestrogens are of most value when assessing fetal growth retardation.

The two main conclusions from this study are that serial ultrasonic cephalometry is significantly better than urinary oestrogens in predicting fetal growth-retardation, but there appears to be no significant difference in the capacity of each method to predict perinatal asphyxia. These findings may appear to be in conflict, but can be explained. Not all small-fordates babies are the result of placental insufficiency-that is, impaired maternal and placental growth support. Some babies are small for their gestational age because the intrinsic growth potential of the fetus is below normal (Naeye, 1965). This is shown by serial cephalometry as an early deviation from the normal growth pattern of the biparietal diameter. However, in view of the fact that placental function is not reduced in such cases, the urinary oestrogens could well be within the normal range. This would also explain why in this study it was only retarded ultrasonic growth rates that were associated with fetal abnormality, as these babies are well known to be small because of low growth potential (Gruenwald, 1969).

Low growth potential, however, is an uncommon cause of the small-for-dates fetus and would account for only a minority of the small babies with normal Apgar scores. The principal explanation is probably that retarded ultrasonic growth rates only reflect impairment of the nutritional function of the placenta. This is usually associated with impairment of the respiratory function, but will often precede it by several weeks. Thus a fetus may show evidence of growth-retardation but may obtain sufficient oxygen via the placenta, even during labour, to preclude neonatal asphyxia. It is therefore likely that ultrasonic cephalometry gives earlier warning of impaired placental 
function than oestrogen excretion. This will assume greater importance if therapeutic measures are discovered that will improve fetal growth in utero.

Failure of the respiratory function of the placenta is also indicated by the number of perinatal deaths, especially those that were small for dates. Of the 11 small-for-dates perinatal deaths, one was in the normal ultrasonic group and two were in the normal oestrogen group. These numbers are too small to draw any comparison between the methods, but it is clear that both tests are successful in defining the group of patients in which respiratory failure of the placenta will occur. Indeed, if we combine the results then all the small-for-dates stillbirths were in the abnormal group of one of the two methods. It should be stressed, however, that when oestrogens are low or ultrasonic growth is retarded it is impossible to predict when intrauterine death will occur.

There is one particular aspect in which ultrasonic cephalometry has a distinct advantage over urinary oestrogens, and that is in the assessment of fetal maturity. It has been previously shown (Campbell, 1969) that measurements taken during the second trimester have a high degree of accuracy in predicting fetal maturity because of the rapid and remarkably uniform growth rate of the fetal biparietal diameter between 13 and 30 weeks' gestation (Campbell and Newman, 1971). Furthermore, Campbell and Dewhurst (1971) found that even after 30 weeks' gestation, if the fetal head was below the normal range but found to be growing normally, the fetal maturity was usually in error, and that the case could safely be allowed to go beyond term provided the growth rate remained normal. Indeed, we have found that cephalometry is efficient in distinguishing between those babies who are small because the maternal dates are in error and those who are small due to fetal growth-retardation, the diagnosis usually being made in one week.

In this study 31 pregnancies were allowed to progress to 43 or more weeks' menstrual age because ultrasonic cephalometry indicated that there was a major error in maturity. Only three of these babies were small for dates, and in two cephalometry showed a terminal flattening of growth. There were no perinatal deaths in this group. Urinary oestrogens, on the other hand, are of no value in indicating fetal maturity and, indeed, can often be misleading for they may be taken by the obstetrician to indicate fetal growth retardation when, in fact, there is a gross error in maturity. For example, nine of the normal cases who were allowed to progress to 43 weeks or more had low oestrogen excretion.

Factors other than diagnostic accuracy also have to be considered, especially when we apply these tests to large numbers of obstetric patients. Ultrasonic apparatus is expensive, but running costs are low and are practically the same as those for urinary oestrogen assay (G. C. V. Chamberlain, personal communication, 1972). Furthermore, as ultrasonic apparatus is of use in the diagnosis of many other obstetric conditions (Donald, 1968), it is likely that most obstetric units will be using this equipment shortly. It is feasible that one operator working full-time could monitor all the at-risk patients for a single hospital. Cephalometry, however, is not easy and considerable experience is necessary before it can be done with consistent accuracy. Furthermore, not all the ultrasonic machines being marketed at the moment are capable of producing accurate results. Urinary oestrogen assay by modern techniques can now be performed in large numbers and up to 40 estimations a day can be made by one technician.

The feasibility of screening the whole obstetric population is now a reality and Beischer and Brown (1972) reported encouraging results from taking routine urine collections at 30 and 36 weeks' gestation. In our experience, however, outpatient urine collections for oestrogen assay frequently give unreliable results, and it is almost mandatory that all patients with low oestrogens should be admitted for inpatient urine collections. This is a disadvantage, as many patients will be admitted unnecessarily. It may be that plasma oestrogens will prove to be more reliable in this respect. It is clear from the present results, however, that if ultrasonic cephalometry is performed in all patients with suspect oestrogens and in the various clinically at-risk pregnancies, then optimal detection of the small-fordates fetus should be achieved.

We thank Mr. G. B. Newman for statistical advice.

\section{References}

Bard, H. (1970). Clinical Obstetrics and Gynecology, 13, 511.

Beischer, N. A., and Brown, J. B. (1972). Obstetrical and Gynecological Survey, 27, 303.

Brown, J. B., and Coyle, M. G. (1963). Fournal of Obstetrics and Gynaecology of the British Commonwealth, 70, 219.

Brown, J. B., MacLeod, S. C., Macnaughtan, C., Smith, M. A., and Smyth,

B. (1968). Fournal of Endocrinology, 42, 5 .
Campbell, S. (1968). Fournal of Obstetrics and Gynaecology of the British Commonwealth, $75,568$.

Campbell, S. (1969), fournal of Obstetrics and Gynaecology of the British Commonzwealth, 76, 603.

Campbell, S. (1971). In Methods for Monitoring the Fetus in Pregnancy and Labour, ed. S. Clayton and R. Beard, p. 83. London, Royal College of Obstetricians and Gynaecologists.

Campbell, S., and Dewhurst, C. J. (1971). Lancet, 2, 1002.

Campbell, S., and Newman, G. B. (1971). Fournal of Obstetrics and Gynaecology of the British Commonzealth, 78, 513.

Diczfalusy, E. (1969). Excerpta Medica Congress Series, 183, 65.

Elder, M. G. (1971). Fournal of Obstetrics and Gynaecology of the British Commonwealth, 78, 123.

Gruenwald, P. (1966). American Fournal of Obstetrics and Gynecology, 94, 1112.

Gruenwald, P. (1969). In Perinatal Problems: Second Report of the 1958 British Perinatal Mortality Survey, ed. N. R. Butler and E. D. AlberBritish Perinatal Mortality Survey, ed. N. R. Butler and E. D. Alber-
man, p. 148. Edinburgh, Livingstone. man, p. 148. Edinburgh, Livingstone.

Jlopper, A. (1965). In Research on Steroids, ed. C. Cassano, Vol. 2, p. 63. Rome, Il Pensiero Scientifico.

Klopper, A. (1969). In Foetus and Placenta, ed. A. Klopper and E. Diczfalusy, p. 471. Oxford, Blackwell Scientific.

Low, J. A., Boston, R. W., and Pancham, S. R. (1972). American fournal of Obstetrics and Gynecology, 113, 351 .

Michie, E. A. (1967). Fournal of Obstetrics and Gynaecology of the British Commonroealth, 74, 896.

Naeye, R. L. (1965). American Fournal of Pathology, 47, 905.

Oakey, R. E., Bradshaw, L. R. A., Eccles, S. S., Stitch, S. R., and Heys, R. F. (1967). Clinical Chimica Acta, 15,35 .

Thomson, A. M., Billewicz, W. Z., and Hytten, F. E. (1968). Fournal of Obstetrics and Gynaecology of the British Commonroealth, 75, 903.

Turnbull, A. C. (1971). In Methods of Monitoring the Fetus in Pregnancy and Labour, ed. S. Clayton and R. Beard, p. 4. London, Royal College

of Obstetricians and Gynaecologists.
Weiner, G. (1970). Fournal of Pediatrics, 76, 694.

Willocks, J., Donald, I., Campbell, S., and Dunsmore, I. R. (1967). 7ournal of Obstetrics and Gynaecology of the British Commonwealth, 